translation for the Chinese word si. Even si has no connotation of any emotional state at all in the Chinese language. Interestingly, Kaptchuk (1983) used the word 'pensiveness' for the word si, which does carry an emotional meaning of melancholy and sadness. How he came to use pensiveness to translate $s i$ is interesting indeed. In the Dictionary of Traditional Chinese Medicine (Beijing Medical College, 1984), si is translated into the word 'anxiety'. Furthermore, not all of the seven emotions were brought into clinical use.

Before the sinologists can translate the Chinese words correctly, and the lexicologists interpret the exact meaning of these words, we are just a group of armchair transcultural psychiatrists studying tautology, philology, analogy, and end up with pleonastic epistemology.

Beuing Medical College (1984) Dictionary of Traditional Chinese Medicine. Hong Kong: The Commercial Press.

KАPTCHUK, T. J. (1983) Chinese Medicine, p. 129. London: Rider.

Department of Psychiatry

Christoph YUNG

Texas Tech University Health Sciences Center 36014 ih Street

Lubbock, Texas 79430, USA

\section{The ethics of resource allocation}

SIR: A point not mentioned by Dr Healy (Journal, January 1993, 162, 23-29) is the enormous savings made every time a long-stay patient is discharged subsequent to clozapine introduction. But there is another matter. Compared with the money spent on computer systems, and information technology departments to service them, the money spent on clozapine is chicken-feed. Has any attempt been made to evaluate the benefit to patients arising from the introduction of so much technology?

\section{Pharmacy Department \\ St Matthew's Hospital \\ Burntwood, Walsall \\ West Midlands WS7 9ES}

\section{Personality disorder and self-report questionnaire}

SIR: Coid (Journal, February 1993, 162, 265) asserted that Dowson (Journal, September 1992, 161, 344-352) had provided evidence that the assessment of personality disorder by self-report instruments is invalid. We have tested a computerised version of Dowson's modified Personality Diagnostic Questionnaire (PDQ) on a group of 20 patients, and clinically assessed each of the positive responses against the DSM-III-R criteria which they are intended to assess. Schizotypal and borderline personality disorders, and many traits in the other categories were significantly overdiagnosed.

A subsequent systematic comparison of the PDQ (modified) with the DSM-III-R criteria indicated, in disagreement with Dowson, that many of the items have poor face validity. Several items have confusing double negatives, and many produce false positive responses. However, the face validity of the clinicianadministered Structured Clinical Interview Schedule (SCID-II) employed by Coid appears high, and this difference could explain the discrepancy. I would therefore question Coid's rather sweeping conclusions that self-report instruments "should not be employed in the future". We are improving the construct validity of our computerised version of the PDQ by rewording many of the items through a process of trial and error. As a self-report assessment instrument of personality, it is becoming clinically useful.

\section{Department of Psychiatry \\ Princess Alexandra's Hospital \\ RAF Wroughton \\ Swindon, Wiltshire SN4 OQJ}

\section{Computerised assessment of depression in the medically ill}

SIR: Meakin (Journal, February 1992, 160, 212-216) states that "the main rival of paper and pencil tests at present is the brief standardised interview", and "there are few other options available as screening tests". We would like to point out another available option overlooked: computer-administered assessment of depression. We recently developed a computer-administered version of the Hamilton Depression Rating Scale (Hamilton, 1960; Kobak et al, 1990). Correlations with the clinicianadministered version of the scale were high (0.96), and the mean score difference was not significant. The scale showed high internal consistency reliability (0.91). Using a cut-off score of 17 , the computer correctly identified $94 \%$ of patients with major depression, and did not incorrectly identify any control subjects as having an affective disorder.

The need for identification and treatment of depression in medically ill, primary care patients is apparent. The National Institute of Mental Health multi-site Epidemiologic Catchment Area study found that while only $31 \%$ of patients identified with an affective disorder had sought help in the previous six months, $45 \%$ of these patients had sought treatment from their primary health care provider for a 
non-psychiatric medical problem (Shapiro et al, 1984). Identification of this large population of untreated, but potentially treatable, group of depressed patients by primary care providers would help reduce the impact of this major health problem. Estimates of the failure rates of primary care physicians in the detection of depression range from $45 \%$ to $90 \%$ (Eisenberg, 1992).

In screening for depression in primary care and psychiatric settings, computers offer several advantages over both clinician-, and paper-and-penciladministered tests. Computer-administered tests are more reliable, due to the standardisation of administration. Computers are not hurried, and do not forget to ask pertinent questions. Computers reduce, or free, clinicians' time, making them cost effective and time efficient. Errors due to scoring or data entry are eliminated, and results can be scored and presented to the physician immediately. In addition, patients may be more likely to disclose information of a sensitive nature, such as suicide, to a computer (Greist et al, 1974).

With the increased use of personal computers, computer-administered applications will become increasingly more common in both psychiatry and general medicine. The availability of valid and reliable computer-administered measures for the assessment of depression can be a valuable tool in assisting the primary care physician with the identification and treatment of this disabling disorder.

EisenberG, L. (1992) Treating depression and anxiety in primary care: closing the gap between knowledge and practice. New England Journal of Medicine, 326, 1080-1083.

Greist, J. H., Gustafson, D. H., Stauss, F. F., et al (1974) Suicide risk prediction: a new approach. Life Threatening Behavior, 4, 212-223.

Hamitron, M. (1960) A rating scale for depression. Journal of Neurology. Neurosurgery and Psychiatry, 23, 56-62.

Kobak, K. A., ReYnolds, W. M., Rosenfeld, R. et al (1990) Development and validation of a computer-administered version of the Hamilton Depression Rating Scale. Psychological Assessment: A Journal of Consulting and Clinical Psychology, 2, 56-63.

Shapiro, S., Skinner, E. A., Kessler, L. G., et al (1984) Utilization of health and mental health services: three epidemiologic catchment area sites. Archives of General Psychiatry, 41, 971-978.

KENNETH A. KobAK

JOHN H. GreisT

Dean Foundation for Health, Research and Education 8000 Excelsior Drive

Madison, Wisconsin, USA 53717

WILLIAM M. REYNOLDS Psychoeducational Research and Training Centre University of British Columbia Vancouver, British Columbia

\section{Community Treatment Order in Australia}

SIR: The recent mauling by a lion of a young man in London with a chronic psychosis has quite rightly reopened the debate on the pros and cons of a Community Supervision (or Treatment) Order (CTO) as part of an amendment to the Mental Health Act.

Having recently returned (temporarily) from Victoria, Australia, where I worked for over two years in an increasingly community-orientated post near Melbourne, I would like to comment on the operation of their CTO which was introduced in the Victorian Mental Health Act (1986).

It soon became clear to me that the CTO was not used a great deal, but that most psychiatrists agreed that it had an important place in the community management of those patients with chronic psychoses who suffer from severe loss of volition and energy, lowered motivation, limited insight, and consequent poor cooperation with their treatment plans. The CTO is especially useful as a means of persuading patients to accept depot neuroleptics or some form of day care on a regular basis. It has very similar provisions to a Hospital Treatment Order, so that it is known from the outset by all concerned that if the patient is non-compliant he/she will be returned to hospital (revocation of the CTO) after receiving the written authority of the treating consultant.

There is, of course, an obvious potential for abuse, but interestingly this is not an issue that patients' rights groups have taken up with vigour. As with inpatients on Treatment Orders, there is the safeguard of automatic, regular review by the Mental Health Review Board (independent review tribunals). The latter's annual reports indicate very few instances of unjustified community 'detention'.

I would like to recommend close scrutiny of the Victorian CTO system in order to ascertain the extent to which it may be applicable and acceptable to the public and health professionals in Britain.

Lakeside Psychiatric Hospital

ANTHONY E. HARDMAN

\section{P.O. Box 63}

Ballarat

Victoria 3353

Australia

\section{Insight in psychosis}

SIR: I read with interest the study by David et al (Journal, November 1992, 161, 599-602) regarding measurement of insight in psychosis. While agreeing that concepts such as the relabelling of events as pathological, and the recognition of having a psychiatric or nervous illness are integral to the concept of 